EPSC Abstracts,

Vol. 3, EPSC2008-A-00434, 2008

European Planetary Science Congress, (C) Author(s) 2008

\title{
Sedimentary deposits in Xanthe Terra: Implications for the ancient climate on Mars
}

\author{
E. Hauber (1), K. Gwinner (1), M. Kleinhans (2), D. Reiss (3), G. Di Achille (4,5), G.-G. Ori (4), F. Scholten (1), \\ L. Marinangeli (4), R. Jaumann (1), G. Neukum (6)
}

(1) Institute of Planetary Research, DLR, Rutherfordstr. 2, 12489 Berlin, Germany, (2) University of Utrecht, Netherlands, (3) Westfälische Wilhelms-Universität, Münster, Germany, (4) Università d`Annunzio, Pescara, Italy, (5) University of Colorado, Boulder, USA, (6) Freie Universität Berlin, Germany (Ernst.Hauber@dlr.de / Fax: +49-30-67055325)

\section{Summary}

A variety of sedimentary deposits is observed in Xanthe Terra, Mars, including Gilbert-type deltas, fan deltas dominated by resedimentation processes, and alluvial fans. Sediments were provided through deeply incised valleys, which were probably incised by both runoff and groundwater sapping. Mass balances based on high-resolution HRSC digital terrain models show that up to $\sim 30 \%$ of the material that was eroded in the valleys is present as deltas or alluvial fan deposits. Stratigraphic relationships and crater counts indicate an age of $\sim 4.0$ to $\sim 3.8 \mathrm{Ga}$ for the fluvial activity. Hydrologic modeling indicates that the deposits were probably formed in geologically very short time-scales. Our results indicate episodes of a warmer and wetter climate on early Mars, followed by a long period of significantly reduced erosion rates.

\section{Background}

Fluvial and lacustrine deposits on Mars contain a record of past hydrological conditions and are important targets of environmental and paleoclimatic studies. Ancient depositional landforms associated with fluvial channels are generally thought to indicate an active hydrosphere, involving precipitation, runoff, and significant erosion. However, the exact nature of the flow processes and the time-scales over which they occurred are under debate. End-member scenarios are represented by an early Mars that was either wet and warm or cold and dry. The analysis of sedimentary deposits can constrain paleohydrological models. For example, a warmer climate and persistent flow would have been required if they were formed in long-standing paleolakes. Alternatively, fans and deltas might have formed under subaerial conditions or in short-lived lakes. Therefore, the determination of the time when such deposits were formed in Mars history, the duration of the fluvial activity, and the type of sedimentary environment is a critical component of paleoclimatic studies of Mars.

\section{Data}

The High Resolution Stereo Camera (HRSC) on the Mars Express spacecraft obtains images which cover very large areas (up to $\sim 3 \times 10^{5} \mathrm{~km}^{2}$ ) with a spatial resolution of typically $12-20 \mathrm{~m} /$ pixel. The instrument is a multiple line scanner, providing stereo images that allow derivation of both high-resolution digital elevation models (DEM) and orthoimages. We used these and other images to investigate the paleohydrology of parts of Xanthe Terra near the equatorial region of Mars. In addition to HRSC image and topographic data, we use the Viking Orbiter Mosaicked Digital Image Model 2.1 (MDIM), images from the Mars Orbiter Camera (MOC), Thermal Emission Imaging System (THEMIS), Context Camera (CTX), and High Resolution Imaging Science Experiment (HiRISE), and Mars Orbiter Laser Altimeter (MOLA) elevation data.

\section{Results}

1) Different types of sedimentary deposits in Xanthe Terra display morphologic similarities to fan deltas (e.g., Fig. 1), while others resemble alluvial fans. They are associated with deeply entrenched valleys, which may have formed by a combination of runoff and sapping. Crater counts on the ejecta of some of the craters that superpose the valleys provide absolute model ages of $\sim 3.8 \mathrm{Ga}$, which would require that fluvial processes operated in the valleys before that time Chronologic and stratigraphic relationships indicate a formation of valleys and deposits in the Late Noachian to Early Hesperian.

2) The formation of the sedimentary deposits occurred probably over relatively short time-scales of several years to $\sim 10^{4}$ years, which is in agreement with previous studies (e.g., 1,2). The general lack of incision of the sedimentary bodies is indicative of an abrupt end of flow, and would be in agreement with an intense terminal period of fluvial activity that ended abruptly $(3,4)$.

3) The relatively well-preserved nature of some small deposits suggests that erosion rates after the sedimentation and the sudden stop of fluvial activity were generally very low.

\section{References}

[1] Jerolmack, D. et al. (2004) GRL, 31, L21701, doi:10.1029/2004GL021326. [2] Kraal, E. et al. (2008) Nature, 451, 973-976. [3] Howard, A. et al. (2005) JGR, 110, CiteID E12S14, doi: 10.1029/2005JE002459. [4] Irwin, R. et al. (2005) JGR, 110, CiteID E12S15, doi: 10.1029/2005JE002460. 

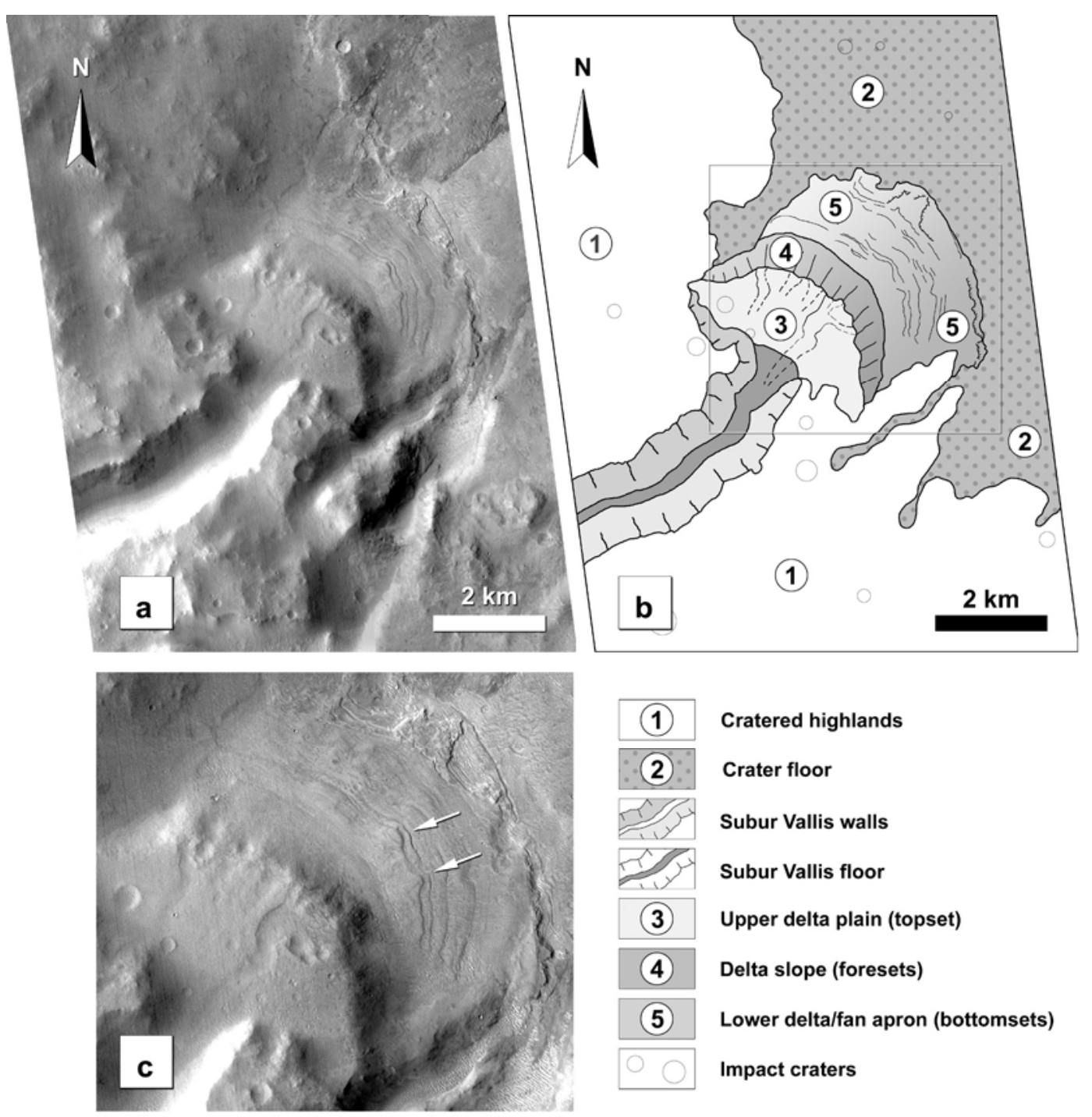

\section{(1) Cratered highlands \\ (2) Crater floor}
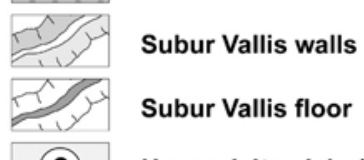

Subur Vallis floor

(3) Upper delta plain (topset)

\section{(4) Delta slope (foresets)}

(5) Lower delta/fan apron (bottomsets) Impact craters

Fig. 1 Gilbert-type delta in unnamed crater at the termination of Subur Vallis (center of delta at $11.72^{\circ} \mathrm{N}$ and $307.05^{\circ} \mathrm{E}$ ). (a) High-resolution view of the downstream part of Subur Vallis and the delta (mosaic of MOC images SP2-52803, E02-00908, R02-00093; white scale bar is $2 \mathrm{~km}$, illumination from the left). (b) morphological sketch map of the delta. Note the well expressed features that are typical for Gilbert-type deltas (flat topset and steep foreset) and the possibly resedimented distal layers (black scale bar is $2 \mathrm{~km}$ ). (c) enlarged detail, marked by white box in panel a. Arrows point to possible depositional lobes, although it can not be excluded that they represent an erosional signature. Indentations of the delta front might have been left by mass wasting processes. 